\title{
The Evidence is IN: Drills are OUT
}

\author{
Wynne Wong \\ The Ohio State University \\ Bill VanPatten \\ The University of Illinois at Chicago
}

Abstract: This article focuses on an aspect of traditional instruction - the form-only activities commonly called "drills," "mechanical practice," or "pattern practice." The authors first distinguish language as an internalized system from language as a productive skill and review the nature of mechanical pratice. They contend that despite claims made about communicative language teaching and its goals, drills and form-only foreign language activities are still widely used in today's classrooms. After reviewing research on the utility of drills, the authors conclude that these activities are not necessary or beneficial for foreign language acquisition or the development of fluency and should be discarded from instructional practice

\section{Introduction}

Ever since Krashen (1982) claimed that second language acquisition (SLA) was an implicit process unaffected by a focus on the formal features of language in the classroom, the profession has debated in some fashion or another the veracity of that claim (e.g., DeKeyser, 1998; Doughty \& Williams, 1998; Hammerly, 1987, 1991; Higgs \& Clifford, 1982; Lightbown \& Spada, 1999; Long, 1983; Schwartz, 1993; Zobl, 1992). The debate has been carried out in both second and foreign language circles and focuses principally on the role of grammar in a communicative language teaching context. (For a good overview of this discussion, see Lightbown \& Spada, 1999, Chapter 6.)

The purpose of this article, rather than to examine this debate, is to evaluate the form-only activities commonly called "drills," "mechanical practice," and "pattern practice," by addressing the question, "Do drills contribute to language acquisition or improved performance over time?" In a sense we are continuing the discussion first launched by VanPatten and Cadierno (1993a, 1993b) that the question is not whether to focus on form but how to focus on form. Our position is that there is sufficient evidence to discard mechanical drills from instructional practice. Our evidence will come from both theory and empirical research.

We would like to make clear that, in our minds, not many of the points we present here are new. A number of them are traceable back to Krashen's claims in one form or another, although it will become clear later that we diverge from his position that a focus on form is neither necessary nor useful. Krashen's points in turn are traceable to others before the initiation of contemporary research on instructed SLA (e.g., Corder, 1967; von Humboldt). What is different is that we may now shift our perspective in language teaching to a more micro level of analysis. Rather than assuming that instruction in and of itself is not necessary or useful, we address the issue that perhaps it is particular aspects of instruction that are neither necessary nor useful.

Wynne Wong (PhD, University of Illinois at Urbana-Champaign) is Assistant Professor of French and Second Language Acquisition at The Ohio State University, Columbus, Ohio.

Bill VanPatten (PhD, University of Texas, Austin) is Professor of Spanish and Second Language Acquisition at The University of Illinois at Chicago, Illinois. 
Before we present our argument, it is important to make a distinction between language as an internalized system and language as productive skill. This distinction is important because how one views the purpose of drills may be influenced by whether one is thinking of a language system or a skill as the object of any instructional effects. Additionally, we need to describe the nature of drills. It is our experience that even though there is a technical definition for drills, some educators assume that any focus on formal features constitutes a "drill." As we will see, this is not the case.

\section{Linguistic System Versus Productive Skill}

There are two aspects to learning a language for oral communicative purposes: the creation of an underlying implicit linguistic system that consists of rules, forms, and lexical items; and the development of the ability to use that system to express meaning. It is a given in contemporary SLA research and theory that all learners, regardless of context (i.e., second vs. foreign language, classroom vs. nonclassroom), must ultimately create an implicit linguistic system in order to be successful language learners and users (e.g., Ellis, 1994; Krashen, 1982; Larsen-Freeman \& Long, 1991; Schwartz, 1993; VanPatten, 2003a; White, 1989). This system is complex and consists of a phonological (sound) system, an abstract syntactic system that governs the nature of sentence structure, a complex network of lexical items and morphological forms (inflections), a pragmatic system that governs how sentences are to be interpreted in context (e.g., is "Why don't you take a rest?" a suggestion or a sincere question that is apropriately answered by "Because ..."), a sociolinguistic system that governs the appropriateness of language use (as dictated by social and communicative context), and a set of discourse rules that govern how sentences and utterances link together to create larger units of meaning. (For a more complete, nontechnical discussion of this system, see VanPatten, 2003a.) As we will show, the development of this complex and implicit linguistic system is not dependent on learner practice of language but rather is dependent on exposure to what is called input.

Different from the development of the linguistic system itself, the development of skill is concerned with such issues as accuracy and fluency during communicative interchanges. Little research has been conducted on how second language learners' accuracy and fluency develop, compared with the extensive body of research on the acquisition of an underlying linguistic system (Schmidt, 1992). What is clear from the work of Pienemann (1998), however, is that the acquisition of output procedures (those procedures used to access lexical items and grammatical forms as well as string them together to make novel sentences) is a process independent of the acquisition of a linguistic sys- tem. In short, learners must simultaneously do two things during the course of acquisition: develop a linguistic system and develop mechanisms for language production. This distinction is important for the present discussion because the utility of drills in language instruction needs to be examined from two different perspectives, namely, whether drills help to develop the underlying system and whether they are useful in promoting accuracy and fluency.

\section{The Nature of Drills}

\section{The Audiolingual Period}

Drills or pattern practice, as they were sometimes called, originated in the 1940s in army language training programs such as those at the Defense Language Institute. These programs employed the Audiolingual Method (ALM), the methodology that would also dominate academic language programs in the country in the 1950s and 1960s. Deeply rooted in structural linguistics and behaviorist psychology (Watson, Skinner), the premise of this methodology was that language learning was basically the result of mechanical habit formation and this habit formation, in turn, was best developed through extensive drilling:

The language class, at early levels, is essentially a drill session. ... As learnings increase, drill turns into discussion, for the student eventually has a stock of structural patterns and lexical items that enable him to express his own intentions and views without, in desperation, being obliged to invent what he has had no model for. If drills have been sufficiently representative and have been fully practiced, analogy will guide the learner along the right linguistic path, as it does in the mother tongue. (Brooks, 1960, p.143)

Proponents of this method believed, as the above quote illustrates, that language learning was guided by analogy and that learners will be able to express their own meaning only after all the necessary structural patterns have been sufficiently drilled into their head. Politzer (1968), for example, believed that pattern practice is important because it gradually moves learners from repetition to self-expression. Error was to be avoided at all costs because repeating an error would result in habitualization of that error. This view is best illustrated by another quote from Brooks (1960): "Like sin, error is to be avoided and its influence overcome, but its presence is to be expected" (p. 58).

One of the most popular series of language learning textbooks that was based on the ALM was by Robert Lado. Each unit in Lado's textbooks typically consisted of the following: (1) a dialog, (2) mechanical pattern drills, and (3) application activities. The following is an example of a mechanical drill:

Do this as a closed-book activity. Tell the students 
that they are to change the sentences you read to them from singular to plural. Go over the examples:

Teacher: He's a lawyer $\rightarrow$ They're lawyers.

Teacher: The class is big.

Student: The classes are big.

Teacher: The student is tall.

Student: The students are tall. (Lado, 1978)

The application activities would require students to do things such as modify or rewrite dialogs for personal expression and very controlled role-plays. The point of these activities was to get students to manipulate memorized material so that they would have practice in applying that material to very controlled communicative situations.

\section{The Eclectic Period}

By the late 1960s and early 1970s, the behaviorist view of language learning was rejected in favor of rationalist and mentalist views. Influenced by Chomsky's linguistic theory and by cognitive psychologists such as Lenneberg (1964) and Ausubel (1968), language was viewed as a rule-governed entity, and meaningful language learning was advocated over rote learning. During this period, there was a shift in emphasis from analogy to analysis in language learning. Rather than mimic language structures, it was now assumed that learners needed to understand and analyze the rules of language in order to build linguistic competence. This new view of language learning was best exemplified in the cognitive-code method, which pushed for meaningful language learning and the development of conscious grammatical knowledge before practice (Chastain, 1976).

In the 1970s, some attempted to bring together the behaviorist and rationalist views of language learning. Carroll (1971) maintained that the theories of behaviorist psychologists, Chomsky, and of cognitive psychologists were compatible, and pushed for an eclectic approach to language learning that combined structural practice with meaningful language use. Paulston (1972, 1976) also shared this view. Citing Katona (1940), she postulated that there are at least "two levels of language" or "two methods of learning": one that is characterized by mechanical skill and one that involves thought or understanding (Paulston, 1976; p. 3). She pushed for an eclectic approach that included grammatical rules and drills that moved from mechanical practice to communicative practice:

... a grammar lesson should consist of grammatical rules which explain the particularities of the structural pattern to be learned plus a series of drills from a mechanical level to a communicative in order to give students optimum practice in language production. (Paulston, 1976, p. 4)
In an attempt to incorporate both the theories of Chomsky and Skinner into language teaching, Paulston proposed a theoretical classification of three types of drills necessary for language learning: mechanical drills, meaningful drills, and communicative drills.

\section{Mechanical drills}

Paulston defined a mechanical drill as one in which there is complete control of the response and only one correct way of responding. Furthermore, because of the complete control of the response, students do not even need to comprehend the stimulus to successfully complete the drill. Paulston (1976, p. 4) provides the following activity on person and noun agreement in Spanish as a mechanical drill:

\section{Model: andar (tú) Response: andas cantar (tú) Response: cantas}

Continue the drill:

$\begin{array}{lll}\text { Cue: } & \text { trabajar }(t u ́) & \text { [Response] } \\ & \text { hablar }(t u ́) & \text { [Response] }\end{array}$

Paulston pointed out that even those who do not know Spanish can successfully do the above drill. In fact, it was suggested that in order to test whether a drill is mechanical or not, nonsense words could be substituted into it; if it can be done this way, then it is a mechanical drill (Paulston, 1976). Paulston stated that these mechanical drills are necessary because they help automatize the use of manipulative patterns:

The expected terminal behavior of such drills is the automatic use of manipulative patterns and is commensurate with the assumption that language learning is habit formation. This involves the classical Skinnerian method of learning through instrumental conditioning by immediate reinforcement of the right response. ... This is a very necessary step in language learning; and as long as the student is learning, he won't mind the mechanical nature of the drill. (p. 6)

\section{Meaningful drills}

Like mechanical drills, meaningful drills are also very controlled and have one right or wrong answer. However, the learner must also comprehend the stimulus. For example, if practicing object pronouns, a teacher might ask "Where does John put his books in class?" The answer is already known by everyone because they can see the books on the rack underneath John's seat. Thus, the answer must be "He puts them under his seat." The answer is completely controlled. Unlike the situation of a mechanical drill, however, the question cannot be answered unless it is understood. Thus, mechanical and meaningful drills are clearly distinguishable. However, even though some kind 
of meaning is involved when engaging in a meaningful drill, according to Paulston (1976), the purpose of meaningful drills is still pattern practice. What Paulston does not explain is why one would need two different kinds of drills to do the same thing.

\section{Communicative drills}

In addition to comprehending the stimulus, communicative drills require learners to also supply information that is not known prior to the drill. Thus, in a communicative drill, there is no right or wrong answer except in terms of grammatical well formedness. Returning to the example of object pronouns, a stimulus in a communicative drill might be "Where do you think John puts his books when he gets home?" Here students may respond with "He puts them on the kitchen counter," "He leaves them on a chair," "He puts them on his desk," and so on. The goal of a communicative drill is "normal speech for communication or, if one prefers, the free transfer of learned language patterns to appropriate situations" (Paulston, 1976, p. 9).

To summarize, Paulston's classification of drills reveals that she is in favor of an approach that begins with habit formation activities that are first mechanical and then meaningful before allowing learners to use language communicatively. She sees her approach as eclectic because it involves a combination of principles that are behaviorist (i.e., habit formation) and cognitive (i.e., analysis of language).

\section{The Prevalence of Drills in FL Instruction}

The sequencing and types of language practice proposed by Paulston have been advocated in one way or another in language methodology texts over the years. As the development of communicative competence took on greater importance with the advent of communicative language teaching, it was finally recognized that instructors must provide learners with opportunities to express their own thoughts, feelings, and reactions. However, structural pattern practice was still regarded as a necessary prerequisite before learners engaged in self-expression.

Littlewood (1980), for example, proposed an approach that focused on the acquisition of "precommunicative" knowledge before allowing learners to engage in communication. In her methodology text, Rivers (1981) provided a checklist to help instructors recognize well-constructed drills. In his Cumulative Mastery Method (CMM), Hammerly (1991) proposed a three-step outline for the sequencing of a lesson: (1) presentation of the rule, (2) manipulation of the rule via mechanical drills followed by meaningful drills, and (3) communication, first with "realistic" communicative activities and finally in "real communication" (p. 142).

As recently as the late 1990s and even in the year 2001, several widely read foreign language methodology texts still advocated, or at least did not question, this type of practice. Stevick (1996) admitted that one of the features of ALM that he liked was the use of "structure drills as a means of internalizing grammar" (p. 218). He also stated that while he did not recommend drills "as either the only or the best starter of free communication," he was also not ready to discard them (p. 172).

Nunan (1999) believed that drills have a place in the classroom but that they may not be sufficient in and of themselves:

[Drills] are an essential ingredient in the learning process for most learners, and provide the enabling skills for later communicative performance. However, by themselves, they do not go far enough in equipping language learners to communicate. (p. 76, emphasis added)

Taking a slightly different view, Omaggio Hadley (2001) did not explicitly advocate the use of mechanical drills. Speaking from a proficiency-oriented instruction perspective, she suggested that a purely mechanical and decontextualized drill is improved when contextualized, as illustrated by the following activities (translated into English), which focused on the use of the subjunctive:

Example 1. Decontextualized Drill

Model: The teacher/to want/the students/to look at/his/books

The teacher wants the students to look at their books.

1. I/to prefer/my/friend/to choose/film/tonight

2. We/to want/tests/to be/easier/etc.

Example 2. Contextualized Drill

Looking for an apartment. Jean-Philippe and his roommate, Paul, want to find a new apartment near the university. Create their conversation, using elements given. Follow the model:

Model: Jean-Philippe: I/to want/the apartment/to be/ near/university

I want the apartment to be near the university. Jean-Philippe: I/prefer/the apartment/to have/a lot/natural light

Paul: And/we/to want/rooms/to be/sufficiently/large Jean-Philippe: You/to be going/insist/they/repaint/ walls?

(Omaggio Hadley, 2001, p. 141-142)

Omaggio Hadley pointed out that the difference between these two examples is that although the first situation cannot be found to exist in the real world, the second contextualized version "links form with meanings that language learners might genuinely want to convey in natural communicative situations" (p. 142). However, her sense of 
the terms meaning and meaningful was not the same as that of Paulston and others. Although Omaggio Hadley did not define these terms, we believe that she meant that providing a context gave the drill meaning. However, learners still do not have to comprehend the stimulus to manipulate it. For example, in the apartment scenario, nonsense words can be inserted and the drill can be completed without problem. For example, in the first item of Omaggio Hadley's contextualized drill, one could substitute the nonsense word blookbeeter for university and still complete the item: I want the apartment to be near the blookbeeter. Substituting the nonsense word doiter for apartment, one can still manipulate the item: I want the doiter to be near the blookbeeter. Thus, contextualized drills are simply mechanical drills with a different introduction or setup.

A final comment on the ubiquity of drills and pattern practice: One can open just about any textbook at the secondary or college level and turn to a section that introduces a grammar point. What one finds is explanation followed immediately by pattern practice, however brief or long this practice phase may be. Workbook and lab manuals contain similar activities. (See also the discussion in Lee \& VanPatten, in press.)

We would also like to point out that our concern is in the belief that mechanical drills are essential for acquisition. We are less concerned about meaningful and communicative drills (à la Paulston) being viewed as essential or beneficial for acquisition, as will become clear later. Thus, in the rest of this paper, we will use the cover terms drill and drills to mean mechanical drills.

\section{A Theoretical Perspective on Why Drills Do Not Work}

Since 1970, the field of SLA research has gathered a tremendous amount of data on both classroom and nonclassroom learners in a variety of contexts (e.g., ESL, EFL, FL in the United States, FL in Europe) and on a variety of languages (e.g., English, Spanish, French, German, Russian, Korean, Japanese). This research has yielded a number of insights and two are of particular importance here. First, learners bring internal mechanisms to the task of acquisition that cannot be manipulated by explicit instruction. Second, learners need access to input, that is, meaningful or communicatively-oriented language that they hear or see and attend to for meaning. We discuss each in the following sections, although our comments must necessarily be brief. We direct the reader to VanPatten (2003a) for a nontechnical discussion of the research and to Larsen-Freeman and Long (1991) and Ellis (1994) for more technical and detailed overviews.

\section{Internal Mechanisms}

By the end of the 1980s, enough research had accumulated to make a number of very important observations about SLA. The first was that learners tend to pass through various stages on their way toward acquiring particular structures. In ESL and EFL contexts, learners each pass through similar stages on their way toward acquisition of negation, auxiliaries, question formation, past tense formation, and tense and aspect distinctions, among others. These stages are universal for all and are not dependent on context or first language of the learners. The research was extended to other languages, and developmental stages have been documented for languages such as German and Spanish (e.g., Pienemann, 1987; VanPatten, 1987).

At the same time, it was found that learners, regardless of first language, also acquired certain surface features of languages (e.g., verb inflections, noun inflections, copular verbs, articles) in a particular order over time and that they do not acquire inflections as "block units." For example, learners of Spanish do not acquire the present tense system and then move on to the past tense system and then move on to the imperfect. Instead, they acquire some inflectional features of the present tense while also acquiring some features of the preterit tense and so on. In addition, classroom learners did not show evidence of acquiring these surface features of language in the order in which they were taught in language courses, and indeed their acquisition orders matched those of learners who acquired language without instruction (e.g., Ellis, 1984, 1989; Pica, 1983). Learners - again, both in and out of the classroom - have demonstrated that the acquisition of the tense and aspectual systems of language (e.g., the use of the preterit/passé composé and imperfect) is piecemeal and unaffected by instructional intervention (Bardovi-Harlig, 2000).

Learners also demonstrated evidence of knowing more than what they were taught and more than what they could have been exposed to. As one example, VanPatten and Mandell (1999) showed that classroom learners of Spanish tended to reject sentences such as Maria ha trabajado y Juan ha tambien, indicating that the sentences were ungrammatical, even though the English counterpart, "Mary has worked and John has, too," is perfectly fine. What is remarkable about this ability to know that something is impossible in Spanish is that these learners were only at the fourth semester level of study, had never been taught anything about "verb deletion," and would certainly never produce it in the types of activities they engaged in as part of their tightly controlled learning experience in the classroom. Furthermore, when queried as to how they knew such sentences in Spanish were not grammatical, they demonstrated evidence of implicit knowledge by overwhelmingly saying something like "It just sounds wrong," whereas when tested on sentences containing errors in subject-verb agreement (an object of explicit instruction in their curriculum), they demonstrated having explicitly 
learned this by saying something like "We learned about this. Verbs have endings that match." What this sample research (and a good deal of other research like it) shows is that learners can "project beyond the evidence" to construct abstract rules of syntax that are not attributable to environmental or external forces (e.g., Schwartz, 1998; White, 1989).

As one final example of the extensive body of research on SLA, first language transfer is not the major error source as once believed by behaviorists and codified in the teaching practices of ALM. The research has clearly shown that learners do not transfer their first language systems in their entirety as part of the learning process. For some reason, learners are "selective" about first language transfer. As just one example, any teacher of French will attest that learners often make the error of saying Je suis vingt ans rather than J'ai vingt ans to communicate that they are 20 years old. The error looks to be a direct transfer of the English sentence "I am 20 years old." However, these same learners misinterpret the passive sentence Le lion a été tué par l'homme as the active, "The lion killed the man" rather than the correct "The lion was killed by the man" (Ervin-Tripp, 1974). The passive structure is identical in French and English and there is no evidence of transfer.

What this basic SLA research has lead to is a series of questions regarding classroom learners:

- Why would learners - in spite of carefully sequenced instruction - not show evidence of having received that carefully sequenced instruction?

- Why would learners pass through strikingly similar stages of acquisition as well as similar acquisition orders in spite of instruction and different first languages?

- Why would learners make some mistakes and not others?

- Why would learners show evidence of first language transfer in some instances and not others?

In short, why doesn't instruction that includes drills and form-only exercises have the effect that its proponents claimed it would?

One answer to these questions could be that instruction is universally bad. That is, everyone everywhere teaches languages poorly, and teachers do not provide instruction as it was meant to be provided under the auspices of ALM and similar approaches. This scenario seems unlikely, given that a good deal of the research is not observational in nature but experimental. In other words, in some of the research instructional design was tightly controlled, a point we will examine later.

A better answer to the above questions is that learners bring to the task certain internal mechanisms that act on the language data to which they are exposed. To put this in lay terms, we can teach whatever we want to, but only the brain is responsible for learning and it has its own devices. Research in SLA has shifted its attention from external variables to internal variables as it seeks to understand just what learners are doing with the language data they encounter in the course of acquisition. We turn our attention now to the question of the data itself.

\section{Input}

Given that learners bring internal mechanisms to the task of acquisition, on what data do these mechanisms operate? It is universally accepted in contemporary SLA theory and research that learners' internal mechanisms work on the data contained in input. To quote one very well-known researcher "The concept of input is perhaps the single most important concept in second language acquisition. ... In fact, no model of second language acquisition does not avail itself of input in trying to explain how learners create second language grammars" (Gass, 1997, p.1). Input is defined as meaning-based language that learners hear or see in context. When confronted with input, the learner's primary goal is to comprehend the speaker's (or writer's) message. Thus, input is communicative in that it exists because someone is attempting to express meaning to a learner. "You need to fill out this form. Here, see? Fill this out. Sign it here on this line," might be said to an immigrant. This is input for that learner. "Open your books to page 24. Is everyone on page 24?" might be said in German to a first-semester German class in college. These examples are considered input because they are couched within some kind of communicative context; somebody is speaking in the second language and attempting to communicate something. To be sure, input is not an explanation of rules or forms. Input is not practice in the language. Input is not consulting a rulebook. It is meaning-based language and involves learner comprehension of an intended message.

What happens to learners is that as they encounter input, their internal mechanisms begin to make connections between formal features of language and the meanings they encode. The mechanisms responsible for syntax work on these data to establish the nature of the syntactic rules the language has. In other words, learner internal mechanisms "deliver" data to other internal mechanisms that actually construct the linguistic system. (We are limiting discussion here to formal features and to syntax because these are the components generally understood by researchers and instructors when we say "grammar.")

As one example, learners of Spanish regularly encounter sentences of the order verb-subject in simple yes/no and WH (when, where, why, who, and how) questions (e.g., Vive Juan con sus padres? "Does John live with his parents?") As the internal mechanisms make note of this word order, they deliver data that indicate the language 
is not a strict subject-verb-object language like English. The consequence of these data is to cause other internal mechanisms (specifically, what is called Universal Grammar) to push the linguistic system towards what is called among linguists "a verb movement" system. In turn, verb movement systems ${ }^{1}$ have certain abstract characteristics (as determined by Universal Grammar) that are then "assumed" by the learner's developing system. The system then simply "waits" for confirming evidence from the input over time. Thus, learners do not have to be taught about verb movement; they simply need to get the data from the input and the internal mechanisms do the rest.

As a simpler example, languages either mark tense on verbs (like Indo-European languages) or they do not (such as Chinese). The data for which kind of language is being learned reside in the input. If the learner encounters caminó in the input and comprehends this in the context of a past tense action of walking, then this connection serves as a trigger to the internal mechanisms that this is a tenseinflected language. The mechanisms then "go on the alert" for other inflections because the system now "knows" that the data must be out there.

It is tempting to react here by saying, "Well, these things are all teachable." Although it is true that many aspects of grammar are teachable, the research is clear that how they are learned does not depend on the teaching. There is no way around it: Only the internal mechanisms that act on input data can create a linguistic system. This now leads us to the problem of drills as an instructional strategy.

It should be evident to the reader that (1) given the fundamental role of input in SLA and (2) given that learners bring internal mechanisms to the task of acquisition that operate on that input, of course drills would be suspect as the initial and/or essential ingredient for internalizing a linguistic system. If their suspect nature is not clear, here are the problems from a theoretical perspective:

1. Input. Drills ask learners to produce a structure or form in order to learn it. But where is the input required for internalization of that structure or form? To state this another way, the use of drills to "cause" acquisition is to put the cart (production) before the horse (input). This is not to say that output is not important; indeed it can be. As we will see in our final section of this paper, output can be critical in stimulating acquisition processes, but does not supplant them.

2. Meaning. The type of input learners need for acquisition is meaning-based or communicative in nature. It must be language to which learners are supposed to respond for its meaning. Drills, by definition, are not meaningful. Recall that Paulston said that drills can be full of nonsense words and learners can still respond in an accurate manner. That is, it depends little on whether the stimulus sentence is "John watched TV" or "Nong betched jaja" - you can still substitute any verb and the learner can correctly produce the past tense if that is the point of the drill. Also recall the basic definition of input for acquisition: meaningbased language that learners hear or see and to which they respond for its message. If drills are meaningless or learners do not have to pay attention to meaning during the exercise, drills cannot be a source of input.

It is true that learners could pay attention to meaning during drills if they wanted to. But this does not get around a more fundamental problem with drills: They involve learner production and not learner comprehension. The learner's job during a drill is not to comprehend but to correctly produce a form or structure. The belief underlying the use of drills is that production of the correct form is acquisition. However, as we indicated above, this is not the universally accepted position of SLA theory and research, and flies in the face of all the evidence when it comes to the creation of an implicit system. Acquisition of a linguistic system is input-dependent, meaning that learners must be engaged in comprehension in order to construct that system. By consistently and constantly having to process linguistic data in the input, learners push the linguistic system along. Production is not comprehension and thus produced language is not input for the learner. That input must come from others.

Is it the case that the language learners produce during drills is input for others? Possibly, but recall that drills do not necessarily involve attention to meaning. If everyone knows that drills are not communicative in nature, then they are not attending to meaning even if someone else is the one producing "language." In short, learners know that drills are for practicing form and not for communicating meaning. As Paulston said so clearly, "Everyone is always aware that these [mechanical and meaningful] drills are only language exercises and that any answer will do as well as another as long as it is grammatically correct and conforms to the information supplied" (Paulston, 1976, p. 7).

To summarize here, based on general SLA research, drills are not necessary for language acquisition when it comes to creating an implicit linguistic system. That they do not qualify as meaning-based input leads to the conclusion that they fall outside the scope of what is necessary for successful SLA. Whether or not they are beneficial is another story, and whether or not they aid in skill development is yet another story. We will address these questions later.

Our argument thus far has been based on theory extrapolated from general SLA research and is unrelated to the actual use of drills. We now turn our attention to research in which drills in the classroom were the object of investigation. 


\section{Early Classroom-Based Research That Questioned Drills}

One of the first empirical studies to undermine the use of drills in the classroom was Savignon's (1972) study of ALM. The study compared three groups of first-semester college L2 French learners. The first group received instruction that consisted of classical ALM training in the classroom four days per week and a lab session one day per week. The lab session consisted mostly of drills. The second group received the same ALM training but instead of the lab session on the fifth day, the students participated in activities that included films, slide shows, and discussions about living and studying in France. The third group also received ALM instruction, but the lab day was devoted to communicative training. Students first were asked to talk about the nature of communication - that is, what it means to communicate and the role of nonverbal communication in face-to-face interactions. Following this, they performed various tasks in French such as greetings, information gathering, and sharing.

Communicative competence was evaluated using four types of activities: (1) conversation with a French native speaker, (2) gathering information via an interview with a French native speaker, (3) performing a monologue on a given topic, and (4) narrating activities of an actor performing a series of nonverbal actions. The results revealed that the third group, who had received training in communication, scored significantly higher than the other groups on all four measures of communicative competence. Conversely, the first group, who only received ALM instruction, scored very low on these tests. This suggests that drills are not effective in developing communicative competence. This study suggested that learning how to communicate results from engaging in communication and not from habit formation by memorizing language patterns.

Another early study that questioned the value of drills was conducted by Lightbown (1983). This longitudinal study set out to examine the relationship between the language that young French-speaking ESL learners hear and the language they produce; specifically, their use of grammatical morphemes in English. Data were obtained from recordings of an oral picture card game. The results revealed that subjects tended to overuse certain grammatical morphemes. For example, they were drilled extensively on the contraction of is with pronouns (e.g., "He is leaving now" $\rightarrow$ "He's leaving now"). After instruction, learners demonstrated a marked tendency to use the contracted is form in places where it should not be used, for example, "He's have three balloons."

Lightbown found that this overuse could be traced back to the speech and practice that these subjects encountered in their classrooms. Students had engaged in memorization and repetitive practice that seemed to result in overlearning. Moreover, when the researcher administered the tests a year later, learners were right back where they were at the initial testing: Their acquisition was apparently delayed. Lightbown concluded that such practice may be harmful to L2 learners' interlanguage development: "By forcing learners to repeat and overlearn forms which have no associated meaning ... we may be setting up barriers which have to be broken down before the learner can begin to build their own interlanguage system" (p. 239).

\section{Contemporary Research that Challenges the Role of Drills}

There is a significant body of more contemporary experimental research showing that drills are not necessary and, in some cases, may have the opposite effect by inducing "nonlearning." These studies compare traditional types of instruction that include drills with an alternative approach to grammar instruction called Processing Instruction (PI) that is devoid of drills. PI has three basic features or components:

1. Learners are given information about a linguistic structure or form.

2. Learners are informed about a particular input processing strategy that may negatively affect their picking up the form/structure during comprehension.

3. Learners are pushed to process the form/structure during activities with structured input - input that is manipulated in particular ways so that learners become dependent on form and structure to get meaning, and/or to privilege the form/structure in the input so that learners have a better chance of attending to it. Learners do not produce the structure or form during structured input activities. (An illustration of this follows.)

The PI approach is designed to avoid specific problems that learners have in processing input, as identified by VanPatten (1996, 2003b). We described earlier that learners need access to input to create linguistic systems. However, access to input does not guarantee correct processing. VanPatten asked, "What do learners do wrong or not well when engaged with input, and can we do something about it?" If we can identify learner strategies or processes for dealing with input, perhaps we can manipulate the input in particular ways to push learners to process it better.

Here is a concrete example with acquisition of the French causative. The causative generally takes the form seen in these two examples.

(1) Jean fait promener le chien à Marie.

(literally: John makes to walk the dog to Mary)

John makes Mary walk the dog.

(2) Mes professeurs me font travailler beaucoup.

(literally: My profs to me make work hard)

My profs make me work hard. 
In (1), there are two verbs and two nouns. The first verb is fait with its obligatorily preposed subject Jean. The second verb is promener with its underlying subject, Marie, obligatorily placed in postverbal position and marked by the preposition $a$. It is the underlying subject of the second verb that is the problem for learners of French. When asked "Who walks the dog?" learners overwhelmingly say "Jean," since Jean is the first noun that appears before the verb. This demonstrates one of the strategies that learners use to process input, a strategy captured in VanPatten's first noun principle. According to VanPatten, learners possess a default strategy that assigns the role of agent (or subject) to the first noun they encounter in a sentence/utterance during comprehension. What this means is that learners do not rely on grammatical clues, such as case markers or noun inflections, to determine who does what to whom; rather, they rely on this simple strategy: The first noun before the verb represents the person (or thing) who does the action. When asked to give a rough translation of (1), learners will say something like "John walks the dog for Mary." Jean is the first noun before the verb promener, so learners misinterpret who did the dog-walking.

In (2), the causative structure is different because the underlying subject of the second verb appears preverbally but not as a subject pronoun. In this case, the pronoun is an indirect object. When asked "Who works hard?" learners will tend to say "My professors," once again demonstrating reliance on the first noun strategy. Their overall interpretation of the sentence is something like "My profs work hard for me." In short, learners tend to gloss over the verb faire and process the second verb only. At the same time, they assign the first noun as subject of the second verb. (See MacDonald \& Heilenman, 1992, as well as the pretest data by Allen, 2000, for research on second language learners sentence processing in French.)

Using knowledge about the effects of the first noun principle on input processing, a PI lesson on the causative would first begin with a brief explanation of what the structure is and looks like. Following this, learners would be told that they have a tendency to process the first noun as the subject of the verb but that this is inappropriate for this structure. Subsequently, they would work through written and aural structured input activities in which they are pushed to process sentences correctly. Here is one example:

Activity A. Listen to each sentence. Then indicate who is performing the action by answering each question.

1. Who cleans the room?

2. Who packs the bags?

etc.

(Teacher's script for Activity A: Read each sentence once. After each sentence, ask for an answer. Do not wait until the end to review answers. Students do not repeat or otherwise produce the structure.)

1. Claude fait nettoyer la chambre à Richard.

2. Marc fait les valises pour Jean.

Continue, mixing causative and noncausative faire.

This example is called a referential structured input activity. Referential activities are those for which there is a right or wrong answer and for which the learner must rely on the targeted grammatical form to get meaning. Normally, a sequence of structured input activities would begin with two or three referential activities. It is important to point out that in the above activities, causative structures with faire are mixed in with noncausatives (e.g., to go skiing in French is faire du ski). In this way, learners are pushed to listen to every sentence and not to think that all sentences are causative just because that is what they are learning.

Following referential activities, learners are engaged in affective structured input activities. These are activities in which learners express an opinion, belief, or some other affective response and are engaged in processing information about the real world. The following is an example:

Activity B. In this activity you will compare and contrast what someone gets a child to do with what someone gets a dog to do. For each item, indicate whether it refers to the small child (à l'enfant), the dog (au chien), or possibly both (à tous les deux).

Un adulte...

1. fait chercher l'os à/au

2. fait faire la vaisselle à/au

3. fait manger à une certaine heure à/au

4. fait jouer dehors à/au

5. fait se baigner à/au

6. fait dormir au plancher à/au

7. fait boire du lait à/au

Does everyone in class agree?

We draw the reader's attention to three differences between these sample activities and a drill. First, during activities A and B, learners do not produce the targeted form or structure. Instead, they must show evidence of having correctly processed it during comprehension. In A, for example, learners simply respond with the name of a person to indicate they understood who did what. In B, they respond with the child, the dog, or both, to show they processed the sentence for its meaning. These activities then engage learners in interpretation of sentences, which means that they qualify as input and not production. Drills, on the other hand, as we have seen, require that learners produce the targeted structure or form. Production is not equivalent to input. 
A second distinction between activities these activities and drills is that in each activity learners are required to pay attention to meaning. In $\mathrm{A}$, for example, to answer the question "Who cleans the room?" is to have demonstrated that the basic meaning of the sentence was understood (i.e., who did what). In B, to indicate whether an action refers to a small child, a dog, or both suggests that the respondent has processed the sentence for meaning. Contrast this with the following situation. If you were asked to determine if the following sentence referred to a child or dog, could you?: "Ganui fatcha a dontiwa ma sumi." Obviously you cannot. If, in activities A and B, learners could not interpret sentences or they interpreted them wrong, the instructor would immediately have evidence that the input was not being processed correctly and the activity could not proceed. In a mechanical drill situation, however, learners could manipulate forms and structures correctly without understanding fully or partially what they are saying. A learner could be told to create a sentence out of these elements, as in the classic "slash sentence" or "dehydrated sentence" drills:

\section{Claude/ nettoyer/ la chambrel à Richard. $\rightarrow$ Claude fait} nettoyer la chambre à Richard.

If we take some nonsense words and insert them, learners can still successfully complete the task:

Claude/bamboyer/la ficel à Richard $\rightarrow$ Claude fait bamboyer la fice à Richard.

The words bamboyer and fice are invented words, yet we are able to create the sentence that is expected of us even though we have no idea what it means.

It is also important to note that because the activity mixes noncausative faire (as in Jean fait du ski avec Marie) with causative structures, learners must pay attention to each sentence to determine whether it is causative or noncausative. Thus, they cannot assume that the answer is always the second noun in the sentence. In a drill, learners can proceed in a rote fashion to complete the exercise.

The third observation to make regarding these activities compared with mechanical drills is that they are designed to cause a change in underlying learner strategies of processing input for acquisition. Recall that learners would approach the French causative using the first noun principle. Activity A, as just one example of several referential activities learners would encounter in this lesson, actually pushes learners away from relying on the first noun principle. As soon as they respond incorrectly to who did what, their internal mechanisms must readjust. In a sense, these mechanisms stop and say, "Tagging the first noun as the subject does not work. There must be other grammatical clues we need to pay attention to." Learners then begin to attend to these clues, thereby delivering important grammatical data for the development of the linguistic system. This is acquisition as described earlier. Drills do not engage the learners' internal mechanisms in this way nor make any attempt to change the processing strategies that learners bring to the task of acquisition. (Evidence for this will be presented shortly.)

There is more to acquisition than the first noun principle and there are problem structures other than the French causative we could discuss here. However, space does not allow further discussion of this. Appendix A presents a list of strategies and processing principles as described in VanPatten (2003b); we also refer the reader to publications that take up both input processing and processing instruction in detail (e.g., VanPatten, 2002, 2003a, 2003b; Wong, 2002, 2003a). Sample items for a complete sequence of structured input activities on the French causative are offered in Appendix B.

\section{Research that Compares Instruction with Drills with Instruction Devoid of Drills}

The first PI study was reported in VanPatten and Cadierno (1993a, 1993b). This study compared PI to traditional approaches to instruction (TI) that consisted of giving learners explicit grammar explanations about the structure followed by output practice activities that started with mechanical drills and then moved to meaningful and communicative drills (Paulston, 1972, 1976). The target of instruction was object pronouns and word order with the "first noun strategy" identified as the problem processing issue. Subjects were randomly assigned to three groups: (1) a PI group, (2) a TI group, and (3) a control group that received no instruction.

In the PI group, learners first received explicit information about how object pronouns work in Spanish. They were also told that learners of Spanish have a tendency to think that the first noun they encounter is the subject, and that this is not an effective strategy because Spanish has a more flexible word order and the first noun is not always the subject. Learners then engaged in a series of structured input activities that pushed them to interpret word order and object pronouns correctly. They received referential activities with right or wrong answers (e.g., "Select the picture that best goes with what you hear") followed by activities that probed them for their opinions or for personal answers. At no point did the learners in this group produce the structure in question or engage in mechanical practice. Subjects in the TI group received an explanation of object pronouns followed by mechanical, then meaningful, then communicative drills. At no time did this group engage in any interpretation activities.

The researchers found that on a sentence-level test of interpretation that required subjects to select pictures that best corresponded to what they had heard, the PI group 
made significant gains, whereas the TI and control groups did not. These gains were maintained on a delayed posttest one month later. On a production test that required learners to complete sentences based on pictures, both the TI and PI groups made significant gains on the immediate and delayed posttests and these gains were not significantly different from each other. The control group did not make significant gains.

These results suggest that PI is more beneficial than TI, because not only did subjects in the PI group gain in ability to interpret object pronouns and word order correctly, they also gained in ability to produce the forms and structure correctly. This is an important finding, because at no time during treatment did subjects in the PI group produce object pronouns, yet, on the production task, they were able to perform as well as subjects in the TI group who received lots of practice in producing this structure. The subjects in the TI group, on the other hand, did not improve on the interpretation task: Their performance was no better than the control group, who received no instruction. This study clearly shows that drills are not necessary.

With the publication of VanPatten and Cadierno's study, a number of questions surfaced and initiated a research agenda on PI. We outline these questions below and the research that subsequently addressed them.

- Can the results of the VanPatten and Cadierno study be generalized to other structures? The answer is yes. Research has been conducted on the following structures with either the same results as VanPatten and Cadierno's study or results that are similar (i.e., PI is superior to TI): preterit tense in Spanish (Cadierno, 1995); future tense in Italian (Benati, 2001); the copular verb estar in Spanish (Cheng, 1995 and 2002); the French causative (VanPatten \& Wong, 2003).

- Can PI be used effectively with any structure or form? The answer, so far, is yes. In addition to PI's effectiveness with the structures listed above, PI is found to also produce significant effects with the simple present vs. progressive in English (Buck, 2000) and with the subjunctive of doubt in Spanish (Farley, 2002, 2003a) as well as the subjunctive with unknown antecedents in Spanish (Collentine, 1998).

- Are the results in VanPatten and Cadierno's study due to the explicit information provided in PI? The answer here is no. In VanPatten and Oikkenon (1996), the researchers compared PI with a group that received structured input-only and another that received the explicit information only. All materials were from VanPatten and Cadierno's study. The researchers found that the PI and structured input only groups made significant gains that were not different from each other. The explicit information-only group made no gains. Thus, structured input alone was sufficient to cause the results we observed. Since the publication of the VanPatten and Oikkenon study, similar results have been obtained by Benati (2003), Farley (2003b), Sanz and Morgan-Short (2002), and Wong (2003b). In every case, structured input alone was enough to cause significant improvement in learner performance and knowledge.

- Are the effects of PI observable on more communicative tests? The answer is yes. VanPatten and Sanz (1995) instructed learners using the materials from VanPatten and Cadierno's study and tested the effects of PI on output measures that went beyond the sentence level. They found that in a video narration task, learners did significantly better after instruction (compared with a control group). Sanz and Morgan-Short (2002) replicated this finding.

- Although PI is better than TI, is it as good or better than meaning-based output instruction? Farley (2002) found PI to be as good as a meaning-based output treatment but not better. However, as Farley argued, the meaning-based output group was not a pure output group because abundant, structured, input-like language was available during the treatment as learners used language with each other and the instructor communicated with them.

- Are the effects of PI long-lasting? In one study, VanPatten and Fernández (2003) used the VanPatten and Cadierno materials to instruct college-level students on object pronouns and word order. They administered a pretest, an immediate posttest, and a delayed posttest eight months after instruction. Although there was a decline in scores on the delayed posttest, learners were still performing significantly better than prior to instruction.

The results of these studies offer a robustness of results that suggest that PI is a very effective grammar-teaching tool. It appears that the results are due to the nature of structured input and not to the explicit information that is a part of PI. Pushing learners to alter their processing strategies positively impacts their developing system. (See also the discussions by Carroll, 2001; Skehan, 1998; and Jordens, 1995.)

Before continuing, we would like to zero in on an important finding in one of the studies. Recall that the VanPatten and Wong (2003) study found that PI was better than TI for the French causative with faire. A further finding in that study was evidence of overusing a rule in the TI group: While scoring the production data, the researchers noticed that those subjects were applying a test-taking strategy. That is, they were making causative constructions with all the test items, including those items that were not causative. Thus, even though they respond- 
ed correctly on the items that required the causative, they really did not learn the causative because they were also making the noncausative items causative. What this means is that even though subjects in the TI group made gains on the production task, it is not clear what they learned; they were simply applying a test-taking strategy. The PI group, on the other hand, was able to distinguish between causative and noncausative constructions. Thus, this study offers evidence that not only are drills not necessary, but TI as such may actually cause students not to learn and to merely "go through the motions."

This first group of studies reviewed above clearly shows that mechanical drills are not necessary. In no study so far does the TI group fair better than a PI group. ${ }^{2}$ In fact, the results strongly suggest that the PI groups that do not include mechanical drills do better overall: They never engaged in mechanical practice and did either better (e.g., on interpretation tests) or as well (e.g., on the production tests) as the TI groups that practiced with mechanical drills on all measures. ${ }^{3}$ Furthermore, when a test-taking strategy was identified, as in a study by VanPatten and Wong (2003), the PI group did better than the TI group on the production task. In this case, the TI group did no better than the no-instruction control group.

\section{Instruction That Shows Learning Gains Without Mechanical Drills}

Research on other types of instruction show that clear gains are made when drills are absent from instruction. Farley (2002), for example, compared PI with meaning-based output instruction (described below) on second year Spanish learners' acquisition of the subjunctive. Subjects were assigned to either a PI group, a meaning-based output instruction (MOI) group, or a control group. Treatment in the PI group was similar to the PI treatments in previous PI studies. Subjects first received explicit information about the formation and use of the subjunctive and then engaged in a series of structured input activities. The activities in the MOI group were all output activities, but unlike activities in TI, they did not have a mechanical component. All the output activities in the MOI group were meaningful and communicative and were based on Lee and VanPatten's concept of structured output (Lee \& VanPatten, 1995; Lee $\&$ VanPatten, in press). The posttests were an interpretation task and a production task. Results on both tasks revealed that both groups had made gains, and there were no significant differences between the two treatments. The gains were maintained one month later.

Silver (2000) compared the performance of three ESL groups with WH-questions after instruction. The groups were an input group (based loosely on, but not equivalent to, PI), an output group that engaged in role plays, and a negotiation group (picture drawing and story completing) in which there were opportunities to interact to co-construct meaning. There was also a control group. Instruction lasted one week. Pretests and posttests consisted of three tasks: an oral communication task, a written task, and a sentence preference task. Although the results were confounded by groups at different proficiency levels at the outset, all groups improved, and the negotiation group made the greatest gains (though partly because they were at a lower level at the outset and had more to gain).

These two studies, different from those presented earlier comparing PI and TI treatments, clearly show that significant improvements can be made in form-focused instruction devoid of drills.

\section{Nontraditional Instruction and Tasks}

Sanz and Morgan-Short (2002) set out to test whether explicit feedback - a component of CALL that is often championed by advocates of technology in language teaching - is necessary or helpful to learners. They chose PI as the method of instruction and used the same materials as VanPatten and Cadierno and VanPatten and Sanz but transferred them to digital media and updated the drawings used in the activities and testing sections. Computer delivery of treatment and testing allowed for randomization and control of all variables involved. Four groups were tested using the variables $+/-$ explanation and $+/-$ explicit feedback. All groups, regardless of the combination of these variables, received the same structured input as practice. No group received output practice of any kind, including drills.

The first group was + explanation (i.e., explicit information about the language and how to process it in the input) and + explicit feedback (defined as not only telling learners whether an answer was correct or not, but what the problem is if incorrect). The second group was explanation and - explicit feedback (structured input only with only indications of whether their answers were right or wrong). The third group was + explanation but - explicit feedback. The fourth group was - explanation but + explicit feedback. All groups received negative feedback in terms of being told whether their answers were correct or not.

Results showed that all groups improved significantly in posttests of the three assessment tasks: interpretation and two production tasks, a sentence completion task, and a video retelling task (there were three posttests as in the original VanPatten and Cadierno study). In addition, no group was better than any other on any task. In short, neither explicit information nor explicit feedback seemed to be crucial for a change in performance; practice in decoding structured input alone (as in the second group) was sufficient (see also VanPatten and Oikkenon, 1996; Wong, 2003b). More to the point here is that all groups improved on the video narration task as well, once again showing that the effects of nontraditional instruction as embodied in 
PI are not limited to improved performance on sentencelevel tasks alone. Drills are not necessary.

\section{Summary}

The research presented above shows that the absence of mechanical drills does not translate into decreased acquisition. Instead, the evidence points to the fact that learners engaged in traditional instruction that includes drills do not fair as well as those engaged in an instructional approach that does not. The PI approach is associated with superior performance on interpretation tests and similar or better performance on production tests; furthermore, the effects are sustained over the long term. From this and the additional studies presented here, we conclude that drills are not necessary and appear not to be beneficial.

\section{Some Possible Objections}

In this section, we address some possible objections to the conclusions of the previous section. We anticipate three objections a reader might raise at this point. The first concerns the role of output in acquisition; since the publication of Swain's (1985) output hypothesis, some have questioned the fundamental role of input in SLA. The second concerns how it is that learners develop automaticity or "fluency and accuracy" if they are not engaged in output practice. The third involves the degree to which the purpose of learning and the nature of the language to be learned make a difference. We address each of these issues in turn.

\section{The Role of Output}

In an influential paper, Swain (1985) argued that in SLA, input alone was insufficient. She claimed that if learners received only a diet of comprehensible input (as suggested by Krashen), they would not move from the semantic processing required for comprehension to the more syntactic processing required for acquisition. Some have mistakenly used Swain's position to create an input versus output debate in SLA (e.g., DeKeyser \& Sokalski, 1996; Salaberry, 1997). These scholars have misinterpreted Swain's hypothesis to mean that either input or output lead to distinct aspects of acquisition or that output itself is the basis for acquisition.

A close reading of Swain's work suggests nothing of the sort. What she argues for is an important if not necessary role for output that stimulates the processes required for acquisition. Swain was absolutely clear that output may have three roles in promoting acquisition (1998). The first role is to promote the noticing of linguistic features in the input. What Swain claims is that by having to produce language, learners may become aware that they cannot say what they want to say. This subsequently pushes them to search (in the input) for ways to express their meaning. A second way in which output promotes acquisition is through hypothesis testing. In this case, learners may hypothesize, but not be sure, how to say something. They subsequently confirm or disconfirm their hypotheses via interaction with more input. A third function of output is to promote conscious awareness of language and language use. Heightened awareness in general may promote those processes that are responsible for acquisition.

What is clear from Swain's discussion is that nowhere is input discarded as a fundamental or critical construct in acquisition. On the contrary, output is seen as something that promotes how learners interact with input for continued growth of their linguistic systems. It is important to note that from the outset Swain argued for the insufficiency of input alone, not that it was unnecessary. Thus, her argument is not for output over input, but rather output in addition to input. What is more, Swain does not argue for drills as a means by which to stimulate acquisition processes. In her view, output is language used in meaningful contexts to communicate information.

Gass (1997), in her discussion of output as negotiation (that is, conversational interaction), perhaps makes the clearest statement on the role of output in SLA:

The claim is not that negotiation causes learning nor that there is a theory of learning based on interaction. Rather, negotiation is the facilitator of learning; it is one means but not the only means of drawing attention to areas of needed change. It is one means by which input can become comprehensible and manageable. (pp. 131-132)

The claim in SLA, then, is not that output can replace input as the means by which acquisition takes place. Output is viewed as something that can influence how learners perceive language and thus interact with input data. Learners become better processors of input because they have to create meaning as part of having to express themselves. They can become aware of deficiencies in their linguistic systems and expressive abilities that push them to acquire more language.

We should underscore that in both Swain's and Gass's positions, output is not meant as "practice of a form." In both cases, output is part of a communicative interaction and may not even involve the production of a form in question. In other words, Swain and Gass are not arguing for drills or drill-like practice; they are arguing for opportunities for learners to engage in self-expression as part of communication. There is no SLA theory or hypothesis that suggests that practicing a form leads to its acquisition.

\section{The Development of Automaticity}

The above discussion leads naturally to the question, "If drilling or practicing a form does not lead to its acquisition, 
can drilling/practice lead to automaticity in production of the form?" Some might interpret the research and theory in skill development within cognitive psychology as an argument for drilling and rote practice. In skill development as discussed by Anderson (2000), learners are seen to move from explicit knowledge of something, to procedural knowledge, and finally to automaticity via practice. The problem with application of skill theory to language acquisition is twofold. First, in a classic skill theory scenario such as learning chess, the novice chess player does not sit around drilling moves. All chess moves occur in the context of playing a game. Thus, whatever chess players learn about playing and however they automatize their moves happens as a result of playing chess, not practicing chess. If we were to apply this to language learning, then the correct application would be that learners do not learn to use forms and structures to express meaning by first practicing them. Instead, learners acquire those forms and structures by consistently using them in communicative situations in which they are required.

The second problem with the wholesale application of cognitive skill theory to SLA is that language is not seen as a system in its own right. That is, the theory would suggest that learning language is like learning tennis, typing, or chess, and would ignore language learners bringing to the task of acquisition certain mechanisms that are specific to language processing (see, Schwartz, 1998, for an excellent discussion of the special nature of language in SLA). In the example we cited earlier from the VanPatten and Mandell study, how could learners come to know that verb deletion in certain constructs in Spanish was impossible without (1) practice in it or (2) evidence via negative feedback from instructors? Currently, skill theory has no means of explaining how it is that all successful learners of a second language come to know more than they were ever taught or practiced, and that this knowledge is of a particular kind and is not based on what skill theorists call "analogy." There is something about language acquisition that cannot be fully explained by skill theory (if at all). For this reason, skill theory as a major explanation of SLA has never been seriously entertained by mainstream researchers in language acquisition.

As for the development of fluency and accuracy (as opposed to the development of the linguistic system itself), skill theory may have something to say. It is possible that learners must produce language in communicative contexts in order to become fluent and accurate communicators, much as chess players need to play chess to become better chess players. However, using language repeatedly in communicative contexts is neither equivalent to drilling nor to constructing the linguistic system itself. Instead, using language repeatedly in communicative contexts relies on the linguistic system. In short, drills do not lead to flu- ency and accuracy in communicative ability.

\section{Context and Target Language}

One of the objections we sometimes hear from colleagues in language teaching is that Russian is "more difficult" or that Japanese is not Indo-European and thus learning these language requires special or different instructional approaches than learning Spanish or French or even English as a second language. It is true that Russian involves a different alphabet and has little Latinate basis on which to rely for teaching and learning in a classroom. It has a complex morphological system for verbs and nouns when compared to English, Spanish, and French. Japanese, too, has a different writing system, no cognates with English, a complicated system of honorifics, and so on. Similar arguments can be made for Amerindian languages like Quechua and Inuit. Nonetheless, learners do acquire these languages without instruction, as is evidenced by the diaries and records of Marco Polo and missionaries who came to the new world, and by the multilingualism that must have existed ever since the first time two different cultures came into contact. But more importantly, a theory of language acquisition cannot change because of language or context. If learners need access to input to acquire a language, this means that all learners of all languages need access to input. If learners pass through stages of acquisition, make certain errors and not others, and their Lls are constrained in terms of transfer, then these are true of all learners regardless of language. Imagine if a scientist suggested that the laws of physics developed on Earth are not applicable to the Moon, Mars, or another galaxy.

Our point here is not that instruction cannot help the learning of Russian, Japanese, or any other language. It is that the role of drills cannot change depending on language. Drills are no more necessary for Russian than they are for Spanish or English. What is plausible, of course, is that learners might need extra help in getting linguistic data from the input. This is precisely the aim of PI as described and discussed in the previous section as well as all the other work on focus on form (Doughty \& Williams, 1998). In one study, Kempe and MacWhinney (1998) showed that learners of Russian could acquire case marking without explicit instruction or drills. This was not the point of their study but we cite it here as an example of research on one of the "more difficult" languages, to illustrate that drills are not necessary: learners can learn Russian from input just like anyone else. They just may need to have it more structured and may need more time.

\section{Meaningful and Communicative Drills}

In this article, we have been occupied primarily with mechanical drills, and believe that there is sufficient evidence to support that they are not necessary for acquisition 
or for teaching. But what of meaningful and communicative drills? Is there research on the necessity or utility of them? The answer is no, although the traditional instruction used in the studies we reviewed earlier did contain the full gamut of mechanical, meaningful, and communicative drills. Thus, those results could be taken to mean that such drills are not particularly useful and certainly are not necessary. However, we refrain from making such a strong claim and leave that open to investigation.

We remind the reader, however, that acquisition is input-dependent. With meaningful and communicative drills, we run into the same problem that we did with mechanical drills: They are all output-oriented. One could certainly question their necessity for the creation of a linguistic system on that basis alone. There are two caveats to this argument, though. First, even though such drills require student output, as Farley notes with his MOI, such output can be input for other students. In this sense, then, meaningful and communicative drills could be of use, but not for the reason advocated by Paulston or most instructors. The second caveat is that although not necessary for acquisition, they could be useful for skill development as long as they are truly meaning-based and involve communication of information.

The danger with meaningful drills, as Paulston herself pointed out years ago, is that their purpose is exactly the same as that of mechanical drills, so students may simply "tune out" their meaning and treat them as form-only exercises - something that we know does not directly aid acquisition. In this case, we would advocate the use of MOI based on structured output activities as in Farley's work. Such activities are task-oriented and contain a type of communication not normally found in most textbook activities that are both output- and form-oriented at the same time. We refer readers to Chapter 6 of Making Communication Language Teaching Happen by Lee and VanPatten (1995) for detailed information on the creation of structured output activities.

\section{"But That's the Way I Learned It"}

From our experience, instructors and instructors-in-training tend to come to language teaching with common sense notions such as "This is how I did it and it worked for me." They mention how they learned from receiving explicit knowledge and then practicing the rules via drills. They follow the logic that if A precedes B then A must cause B. In this case, $\mathrm{A}=$ explanation + practice (à la Paulston) and $\mathrm{B}=$ eventual ability to use the language. There are two problems with this reasoning. The first involves confusion between explicit learning and acquisition. We do not deny that someone can learn a rule, practice it, and gain some kind of ability with that rule. What we reject is that this ability represents acquisition as defined in this paper and in
SLA in general.

The second problem with the A-precedes-B logic is that A may have preceded B, but that $\mathrm{C}$ (and D and $\mathrm{E}$ ) were also present at some point and may be the fundamental building blocks of acquisition. No advanced speaker or near native speaker ever studied has learned language exclusively through explanation and practice. Every advanced and successful learner has lived abroad, interacted with other speakers, read in the second language, seen films and perhaps watched TV, perhaps purchased music and listened to songs in the second language, and so on. These activities all suggest interaction with input, and as early research clearly showed, learners do not advance significantly without extensive study abroad (Carroll, 1967). Learners are not engaged in mechanical drilling with native speakers while studying abroad.

\section{Conclusion}

In this article, we have described a body of evidence that strongly suggests the following:

- Drills are not necessary. We provided evidence for this in contemporary research that contrasts PI with TI and research that examined the outcomes of other meaning-based approaches to grammar instruction or focus on form.

- In some cases, drills can impede acquisition. We saw this in the Lightbown study in which, in spite of intensive pattern practice, learners' natural acquisition strategies reasserted themselves. These strategies are seen to be necessary for the development of the learner's internal grammar. In the case of the subjects in the Lightbown study, it was evident that the subjects basically lost a year that could have been devoted to activities that promoted acquisition. In the VanPatten and Wong study, we saw that using a drill sequence as Paulston advocated did not actually result in learning the target structure but in performing a particular task that learners subsequently used as a test taking-strategy.

- Well-articulated, meaning-based approaches predicated on what we know about the psycholinguistics of SLA are often better and certainly always as good as traditional approaches that make use of drills. We saw this most strongly in the case of the research on PI. We also saw it in the Farley and Silver studies in which significant gains were made in the absence of drills and pattern practice.

To be clear, we also want to state what we are not claiming. By claiming that drills are not necessary and in some cases can hinder acquisition, we are not saying that no focus on form is necessary or that we are against instruction of any kind. Our position is clearly different 
from the position taken by Krashen (1982) and others. We are obviously advocating some kind of focus on form, given the research we have been involved in regarding PI. That is, PI is explicit instruction and it is interventionist in nature. It is merely different because it is informed by research on input processing in SLA. Although it remains to be shown that focus on form is necessary for all learners in all contexts, we do believe that focus on form can at least be beneficial to most if not all learners if it is informed by what we know about processes involved in acquisition.

We are also not claiming that learners do not need to produce language in order to acquire language. What we believe is that an internal grammar is built up via exposure to comprehensible, communicatively oriented input - a position that is unquestioned in the field of SLA after four decades of research. We see a role for production (or output) as a means of developing fluency and accuracy as the learner draws upon that internal grammar to express meaning (e.g., see Lee \& VanPatten, in press). We also believe that in some instances, interaction in which meaning is negotiated can bring a grammatical form into the learner's realm of attention as he or she hears it spoken by the interlocutor (e.g., Gass, 1997; Lee \& VanPatten, in press; VanPatten, 2003a). What we are stating in this article comes down to this: As far as acquisition is concerned, drills are simply unnecessary and at best a waste of time for the development of communicative language ability.

\section{Acknowledgments}

We would like to thank several colleagues and graduate students who read earlier drafts of this paper and commented on it for us: Janice Aski, Laëtitia Bramoullé, Frank B. Brooks, and Amy Overmyer. We would also like to thank the anonymous reviewers and FLA editor Emily Spinelli for insightful comments that helped us improve the clarity of our discussion. All errors in content, of course, are traceable to us.

\section{Notes}

1. A discussion of technical and abstract nature of verb movement is beyond the scope of the present paper. We refer the reader who wishes to pursue discussion to Lightfoot and Hornstein (1994).

2. There is one study (Allen, 2000) that purports to research PI versus TI and that yielded one anomalous result in which TI is slightly better than PI. However, this study is flawed in both method and design: Most importantly, the TI group was actually a mix of traditional and processing activities. In addition, the structured input activities in the PI group did not lead students to make form-meaning connections, but to apply a rote strategy. For these reasons, we have not included the study in our discussion here. See VanPatten (2002) as well as VanPatten and Wong (2003) for detailed comments on that particular study.
3. We would like to remind readers that the activities in the TI groups were not exclusively mechanical. They were created following the sequence recommended by Paulston $(1972,1976)$ : first mechanical, then meaningful, and then communicative.

\section{References}

Allen, L. Q. (2000). Form-meaning connections and the French causative: An experiment in Processing Instruction. Studies in Second Language Acquisition, 22, 69-84.

Anderson, J. R. (2000). Learning and memory: An integrated approach. New York: Wiley.

Ausubel, D. (1968). Educational psychology: A cognitive view. New York: Holt, Rinehart, \& Winston.

Bardovi-Harlig, K. (2000). Tense and aspect in second language acquisition: Form, meaning, and use. Oxford: Blackwell.

Benati, A. (2001). A comparative study of the effects of processing instruction and output-based instruction on the acquisition of the Italian future tense. Language Teaching Research, 5, 95-127.

Benati, A. (2003). The effects of structured input activities and explicit information on the acquisition of Italian tense. In B. VanPatten (Ed.), Processing instruction. Hillsdale, NJ: Erlbaum.

Brooks, N. (1960). Language and language learning. New York: Harcourt.

Buck, M. (2000). Procesamiento del lenguaje y adquisición de una segunda lengua. Un estudio de la adquisición de un punto gramatical en inglés por hispanohablantes. Doctoral thesis; Universidad Nacional Autónoma de México.

Cadierno, T. (1995). Formal instruction in processing perspective: An investigation into the Spanish past tense. The Modern Language Journal, 79, 179-194.

Carroll, J. B. (1967). Foreign language proficiency levels attained by language majors near graduation from college. Foreign Language Annals, 1, 131-151.

Carroll, J. B. (1971). Current issues in psycholinguistics and second language teaching. TESOL Quarterly, 5, 101-114.

Carroll, S.E. (2001). Input and evidence. Philadelphia: John Benjamins.

Chastain, K. (1976). Developing second language skills: Theory to practice (2nd ed.) Chicago: Rand McNally.

Cheng, A. (1995). Grammar instruction and input processing: The acquisition of Spanish ser and estar. Doctoral thesis; University of Illinois at Urbana-Champaign.

Cheng, A. (2002). The effects of processing instruction on the acquisition of ser and estar. Hispania, 85, 308-323.

Collentine, J. G. (1998). Processing instruction and the subjunctive. Hispania, 81, 576-587.

Corder, S. P. (1967). The significance of learners' errors. International Review of Applied Linguistics, 5, 161-170.

DeKeyser, R. (1998). Beyond focus on form: Cognitive perspectives on learning and practicing second language grammar. In C. Doughty \& J. Williams (Eds.), Focus on form in classroom second language acquisition (pp. 42-63). New York: Cambridge 
University Press.

DeKeyser, R., \& Sokalski, K. (1996). The differential role of comprehension and production practice. Language Learning, 46, 613-642.

Doughty, C., \& Williams, J. (1998). Focus on form in classroom second language acquisition. New York: Cambridge University Press.

Ellis, R. (1984). Classroom second language development. London: Pergamon.

Ellis, R. (1989). Are classroom and naturalistic acquisition the same? A study of the classroom acquisition of German word order rules. Studies in Second Language Acquisition, 11, 305-328.

Ellis, R. (1994). The study of second language acquisition. Oxford: Oxford University Press.

Ervin-Tripp, S. (1974). Is second language learning like the first? TESOL Quarterly, 8, 111-127.

Farley, A. P. (2002). Authentic processing instruction and the Spanish subjunctive. Hispania, 84, 289-299.

Farley, A. P. (2003a). The relative effects of processing instruction and meaning-based output instruction. In B. VanPatten (Ed.), Processing instruction. Mahwah, NJ: Erlbaum.

Farley, A. P. (2003b). Processing instruction and the Spanish subjunctive: Is explicit information needed? In B. VanPatten (Ed.), Processing instruction. Mahwah, NJ: Erlbaum.

Gass, S. M. (1997). Input and interaction in second language acquisition. Mahwah, NJ: Earlbaum.

Hammerly, H. (1987). The immersion approach: Litmus test of second language acquisition through classroom communication. The Modern Language Journal, 71, 395-401.

Hammerly, H. (1991). Fluency and accuracy: Toward balance in language teaching and learning. Clevedon: Multilingual Matters.

Higgs, T. V., \& Clifford, R. (1982). The push toward communication. In T. V. Higgs (Ed.), Curriculum, competence, and the foreign language teacher (pp. 57-79). Skokie, IL: National Textbook.

Jordens, P. (1996). Input and instruction in second language acquisition. In P. Jordens \& J. Lalleman (Eds.), Investigating second language acquisition (pp. 407-449). Berlin: Mouton de Gruyter.

Katona, G. (1940). Organizing and memorizing. New York.

Kempe, V., \& MacWhinney, B. (1998). The acquisition of case marking by adult learners of Russian and German. Studies in Second Language Acquisition, 20, 543-587.

Krashen, S. (1982). Principles and practice in second language acquisition. New York: Pergamon.

Lado, R. (1978). Lado English series: Teacher's manual 1. New York: Regents.

Larsen-Freeman, D., \& Long, M. H. (1991). An introduction to second language acquisition research. London: Longman.

Lee, J., \& VanPatten, B. (1995). Making communicative language teaching happen. New York: McGraw Hill.

Lee, J., \& VanPatten, B. (in press). Making communicative lan- guage teaching happen. Second Edition. New York: McGraw Hill.

Lenneberg, E. (1964). New directions in the study of language. Cambridge, Mass: M.I.T. Press.

Lightbown, P. (1983). Exploring relationships between developmental and instructional sequences in L2 acquisition. In $\mathrm{H}$. Seliger \& M. Long (Eds.), Classroom-oriented research in second language acquisition, (pp. 217-243). Rowley, MA: Newbury House.

Lightbown, P. M., \& Spada, N. (1999). How languages are learned. Oxford: Oxford University Press.

Lightfoot, D., \& Hornstein, N. (1994). Verb movement. Cambridge: Cambridge University Press.

Littlewood, W. (1980). Form and meaning in language teaching methodology. The Modern Language Journal, 64, 441-445.

Long, M. H. (1983). Does second language instruction make a difference? A review of the research. TESOL Quarterly, 17, 359-382.

MacDonald, J. L., \& Heilenman, L. K. (1992). Changes in sentence processing as second language proficiency increases. In R. J. Harris (Ed.), Cognitive processing in bilinguals (pp. 325-336). New York: Elsevier Science.

Nunan, D. (1999). Second language teaching and learning. Boston: Heinle \& Heinle.

Omaggio Hadley, A. (2001). Teaching language in context. Boston: Heinle \& Heinle.

Paulston, C. B. (1972). Structural pattern drills: A classification. In H. Allen \& R. Campell (Eds.), Teaching English as a second language (pp. 129-138). New York: McGraw Hill.

Paulston, C. B. (1976). Teaching English as a second language: Techniques and procedures. Cambridge: Winthrop Publishers.

Pica, T. (1983). Adult acquisition of English as a second language under different conditions of exposure. Language Learning, 33, 285-296.

Pienemann, M. (1987). Psychological constraints on the teachability of languages. In C. Pfaff (Ed.), First and second language acquisition processes (pp. 143-168). Rowley, MA: Newbury House.

Pienemann, M. (1998). Language processing and second language development: processability theory. Philadelphia: Benjamins.

Politzer, R. (1968). The role and place of the explanation in the pattern drill. International Review of Applied Linguistics, 6, 315-331.

Rivers, W. M. (1981). Teaching foreign language skills. Chicago: University of Chicago Press.

Salaberry, M. R. (1997). The role of input and output practice in second language acquisition. The Canadian Modern Language Review, 53, 422-451.

Sanz, C., \& Morgan-Short, K. (2002). Must computers deliver explicit feedback? An Empirical Study. Paper delivered at the February 21-24 2002 conference on Form-meaning Connections in Second Language Acquisition; Chicago.

Savignon, S. (1972). Communicative competence: An experiment in foreign language teaching. Philadelphia: Center for 
Curriculum Development.

Schmidt, R. W. (1992). Psychological mechanisms underlying second language fluency. Studies in Second Language Acquisition, 14, 357-385.

Schwartz, B. D. (1993). On explicit and negative data affecting competence and linguistic behavior. Studies in Second Language Acquisition, 15, 147-163.

Schwartz, B. D. (1998). The second language instinct. Lingua, 106, 133-160.

Silver, R. (2000). Input, output, and negotiation: Conditions for second language development. In. B. Swierzbin, F. Morris, M. E. Anderson, C. A. Klee, \& E. Tarone (Eds.), Social and cognitive factors in second language acquisition: Selected proceedings of the 1999 Second Language Research Forum (pp. 345-371). Somerville, MA: Cascadilla.

Skehan, P. (1998). A cognitive approach to language learning. Oxford: Oxford University Press.

Stevick, E. (1996). Memory, meaning, and method: A view of language teaching. Boston: Heinle \& Heinle.

Swain, M. (1985). Communicative competence: Some roles of comprehensible input and comprehensible output in its development. In S. M. Gass \& C. Madden (Eds.), Input in second language acquisition (pp. 235-253). Rowley, MA: Newbury House.

Swain, M. (1998). Focus on form through conscious reflection. In C. Doughty \& J. Williams (Eds.), Focus on form in classroom second language acquisition (pp. 64-81). Cambridge: Cambridge University Press.

VanPatten, B. (1987). Classroom learners' acquisition of ser and estar: Accounting for developmental patterns. In B. VanPatten, T. Dvorak, \& J. Lee (Eds.), Foreign language learning: A research perspective (pp. 61-75). Cambridge: Newbury House.

VanPatten, B. (1996). Input processing and grammar instruction: Theory and Research. Norwood, NJ: Ablex.

VanPatten, B. (2002). Processing instruction: An update. Language Learning, 52, 755-803.

VanPatten, B. (2003a). From input to output: A teacher's guide to second language acquisition. New York: McGraw-Hill.
VanPatten, B. (2003b). Input processing in SLA. In B. VanPatten (Ed.), Processing instruction. Mahwah, NJ: Erlbaum.

VanPatten, B., \& Cadierno, T. (1993a). Explicit instruction and input processing. Studies in Second Language Acquisition, 15, 225-243.

VanPatten, B., \& Cadierno, T. (1993b). Input processing and second language acquisition: A role for instruction. The Modern Language Journal, 77, 45-57.

VanPatten, B., \& Fernández, C. (2003). The long-term effects of processing instruction. In B. VanPatten (Ed.), Processing instruction. Mahwah, NJ: Erlbaum.

VanPatten, B., \& Mandell, P. (1999). Does structure-type affect how learners render grammaticality judgments? Paper delivered at the March 8-10 1999 annual meeting of the American Association for Applied Linguistics; Stamford, CT.

VanPatten, B., \& Oikkenon, S. (1996). Explanation versus structured input in processing instruction. Studies in Second Language Acquisition, 18, 495-510.

VanPatten, B., \& Sanz, C. (1995). From input to output: Processing instruction and communicative tasks. In F. Eckman, D. Highland, P. Lee, J. Mileham, \& R. Rutkowski Weber (Eds.), Second language acquisition theory and pedagogy (pp. 169-185). Mahwah, NJ: Earlbaum.

VanPatten, B., \& Wong, W. (2003). Processing instruction and the French causative: A replication. In B. VanPatten (Ed.) Processing instruction. Mahwah, NJ: Erlbaum.

White, L. (1989). Universal grammar and second language acquisition. Amsterdam: John Benjamins.

Wong, W. (2002). Linking form and meaning: Processing Instruction. The French Review, 76, 236-264.

Wong, W. (2003a). The nature of processing instruction. In B. VanPatten (Ed.), Processing instruction. Mahwah, NJ: Erlbaum.

Wong, W. (2003b). Processing instruction in French: The roles of explicit information and structured input. In B. VanPatten (Ed.), Processing instruction. Mahwah, NJ: Erlbaum.

Zobl, H. (1992). Sources of linguistic knowledge and uniformity of nonnative performance. Studies in Second Language Acquisition, 14, 387-403. 


\section{Appendix A}

Principles of Input Processing (based on VanPatten, 2003b)

Principle 1. The Primacy of Meaning Principle. Learners process input for meaning before they process it for form.

P1a. The Primacy of Content Words Principle. Learners process content words in the input before anything else.

P1b. The Lexical Preference Principle. Learners will tend to rely on lexical items as opposed to grammatical form to get meaning when both encode the same semantic information.

P1c. The Preference for Nonredundancy Principle. Learners are more likely to process nonredundant meaningful grammatical form before they process redundant meaningful forms.

P1d. The Meaning-Before-Nonmeaning Principle. Learners are more likely to process meaningful grammatical forms before nonmeaninful forms irrespective of redundancy.

P1e. The Availability of Resources Principle. For learners to process either redundant meaningful grammatical forms or nonmeaningful forms, the processing of overall sentential meaning must not drain available processing resources.

P1f. The Sentence Location Principle. Learners tend to process items in sentence initial position before those in final position and those in medial position.

Principle 2. The First Noun Principle. Learners tend to process the first noun or pronoun they encounter in a sentence as the subject/agent.

P2a. The Lexical Semantics Principle. Learners may rely on lexical semantics, where possible, instead of word order to interpret sentences.

P2b. The Event Probabilities Principle. Learners may rely on event probabilities, where possible, instead of word order to interpret sentences.

P2c. The Contextual Constraint Principle. Learners may rely less on the First Noun Principle if preceding context constrains the possible interpretation of a clause or sentence.

\section{Appendix B}

\section{Sample Items for a Set of Structured Input Activities for faire causatif}

\section{Activité A}

Listen to each sentence. Then indicate who is performing the action by answering each question.

1. Who cleans the room?

2. Who packs the bags?

3. Who watches the movie?

4. Who sings in public?

(Activity A Teacher's script: Read each sentence once. After each sentence, ask for an answer. Do not wait until the end to review answers. Students do not repeat or otherwise produce the structure.)

1. Claude fait nettoyer la chambre à Richard.

2. Marc fait les valises pour Jean.

3. Sandra fait voir le film à Pierre.

4. Louis fait chanter en publique à Suzanne.

\section{Activité B}

Listen to each sentence then indicate what it means in English.

1. a. Lucie paints the walls. b. Lucie has the walls painted.

2. a. Robert builds a house. b. Robert has a house built.

3. a. Marie does chores. b. Marie has the chores done. 
(Activity B Teacher's script: Read each sentence once. Review the answer after each question; do not wait until the end to review answers. Students do not repeat or otherwise produce the structure.)

1. Lucie fait peindre les murs.

2. Robert fait construire une maison.

3. Marie fait les devoirs.

\section{Activité C}

Read each sentence then decide whether or not it is typical of a parent-child relationship. Imagine the child is 10 years old. Un parent ...

1. fait faire les devoirs à son enfant.

2. fait étudier chaque soir à son enfant.

3. fait faire de l'exercise à son enfant.

4. fait nettoyer la salle de bain à son enfant.

C'est typique Ce n'est pas typique

Now, repeat the above but this time imagine that the child is 18 and still lives at home. Do any answers change?

(Activity C Teacher's Script: When reviewing the activity as a group, you read out loud the item and students respond only with c'est typique or ce n'est pas typique. Students do not repeat or otherwise produce the structure.)

\section{Activité D}

In this activity you will compare and contrast what someone gets a child to do with what someone gets a dog to do. For each item, indicate whether it refers to the small child (à l'enfant), the dog (au chien) or possibly both (à tous les deux).

Un adulte ...

1. fait chercher l'os (bone) à/au

2. fait faire la vaisselle à/au

3. fait jouer dehors à/au

4. fait prendre un bain à/au

Does everyone in class agree?

(Activity D Teacher's note: Conduct as in Activity C.)

\section{Activité E}

Listen to the sentences and indicate the most likely scenario.
1. a. We watch TV.
b. Jack watches TV.

2. a. We write the paper.

b. She writes the paper for us.

3. a. She does the dishes.

b. Her mom does the dishes.

(Activity E Teacher's script: Read each sentence once. After each sentence, ask for an answer. Do not wait until the end to review answers. Students do not repeat or otherwise produce the structure.)

1. Nous faisons regarder la télé à Jacques.

2. Elle nous fait écrire le travail.

3. Elle fait la vaisselle pour sa mère.

\section{Activité F}

Listen as your instructor makes a statement about what your university makes him or her do. Decide whether it is true or false.

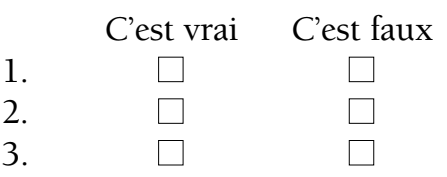

(Activity F Teacher's script: Conduct like activities C-E above. Students do not repeat or otherwise produce the structure.) 1. Luniversité me fait donner trois cours chaque semestre.

2. Luniversité me fait limiter le nombre des étudiants dans chaque cours. 
3. Luniversité me fait rester à la maison si je suis malade.

\section{Activité G}

Finish the four statements in your own way to indicate something that your instructor gets you and your classmates to do regularly or occasionally. Then compare with the class. Did you all write similar things?

Le professeur...

1. nous fait écrire

2. nous fait lire

3. nous fait travailler

4. nous fait regarder

(Activité G Teacher's script: Allow students about 4-5 minutes to complete the sentences. Then call on one student to read item one aloud. Survey the class to see who wrote something similar or different. Go back to the first student and have him/her read item 2. Repeat until all items are done.) 